\title{
Perineal Erythema in Kawasaki Disease and MIS-C
}

\author{
María Teresita Sánchez-Alarcón ${ }^{1}$ • Itzel Estefani Ríos-Olivares ${ }^{2}$ • Alonso Gutiérrez-Hernández ${ }^{1}$.

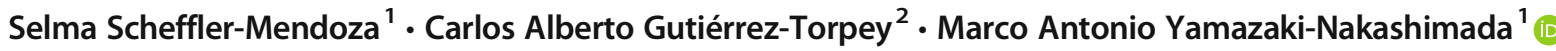

Received: 25 January 2021 / Accepted: 24 February 2021 / Published online: 13 March 2021

(C) Dr. K C Chaudhuri Foundation 2021

An 8-y-old boy presented with a history of fever, abdominal pain, diarrea, and a polymorphic rash. He developed vomiting, conjunctival injection, and fissured lips. Physical exam revealed adenopathy and a desquamative polymorphic eryhtematous rash over abdomen, extremities, and perineum (Fig. 1). Periungual desquamation was found in fingers of hands and feet. Laboratory tests showed anemia, leukocytosis, thrombocytosis, and elevated erythrocyte sedimentation rate, $\mathrm{C}$-reactive protein (CRP), pro-brain natriuretic peptide (proBNP) and fibrinogen. Reverse transcription polymerase chain reaction (RT-PCR) for severe acute respiratory syndrome coronavirus 2 (SARS-CoV-2) was negative but immunoglobulin $\mathrm{G}$ ( $\mathrm{IgG}$ ) was positive. An echocardiogram showed aneurysms of left main coronary, left circumflex, left anterior descending, and right coronary arteries. The patient was treated with intravenous gammaglobulin (IVIG), methylprednisolone, enoxaparin, and aspirin. He continued to have fever and was retreated with IVIG, infliximab and cyclosporine with good response. Perineal erythema is a characteristic clinical finding in Kawasaki disease (KD) [1]. Kim et al. reported the first Korean patient with multisystemic inflammatory syndrome in children (MISC) who presented with perianal erythema with desquamation [2]. Mazori et al. also reported cases of MIS-C with perineal erythema [3]. The clinical similarities and response to similar therapy opens the possibility that MIS$\mathrm{C}$ is a part of KD spectrum triggered by SARS-CoV2. The

Marco Antonio Yamazaki-Nakashimada yzki71@yahoo.com.mx

1 Clinical Immunology Department, Instituto Nacional de Pediatría, Insurgentes Sur 3700-C, Insurgentes Cuicuilco, Coyoacán, 04530 Mexico City, CP, Mexico

2 Pediatric Cardiology Department, Instituto Nacional de Pediatría, Insurgentes Sur 3700-C, Insurgentes Cuicuilco, Coyoacán, 04530 Mexico City, CP, Mexico

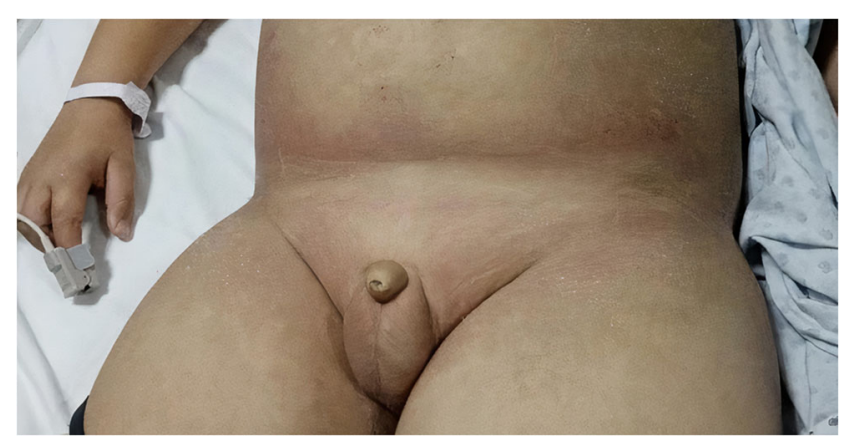

Fig. 1 Perineal erythema with desquamation involving the diaper area

presence of perineal erythema gives an argument to consider MIS-C as part of the KD spectrum.

\section{Declarations}

Conflict of Interest None.

\section{References}

1. McCrindle BW, Rowley AH, Newburger JW, et al; American Heart Association Rheumatic Fever, Endocarditis, and Kawasaki Disease Committee of the Council on Cardiovascular Disease in the Young; Council on Cardiovascular and Stroke Nursing; Council on Cardiovascular Surgery and Anesthesia; and Council on Epidemiology and Prevention. Diagnosis, treatment, and long-term management of kawasaki disease: a scientific statement for health professionals from the American Heart Association. Circulation. 2017; 135:e927-99.

2. Kim H, Shim JY, Ko JH, et al. Multisystem inflammatory syndrome in children related to COVID-19: the first case in Korea. J Korean Med Sci. 2020;35(43):e391. https://doi.org/10.3346/jkms.2020.35. e391.

3. Mazori DR, Derrick KM, Kapoor U, Haribhai M, Gist RE, Glick SA. Perineal desquamation: an early sign of the Kawasaki disease phenotype of MIS-C. Pediatr Dermatol. 2020. https://doi.org/10.1111/ pde.14462.Onlineaheadofprint.

Publisher's Note Springer Nature remains neutral with regard to jurisdictional claims in published maps and institutional affiliations. 